\title{
Application of Charging Mobile Phone by Solar Energy
}

\author{
${ }^{1}$ Mohamed Abdulhadi Elmahdi, ${ }^{2}$ Prof.Ir. Sudjito.Suparman,PHD, \\ ${ }^{3}$ Dr. Ir. Sholeh Hadi Pramono, MS \\ Department of Electrical Engineering, Brawijaya University
}

\begin{abstract}
The ability to harvest energy from the environment represents an important technology area that promises to eliminate wires and battery maintenance for many important applications and permits deploying self powered devices. This paper suggests the Application of Charging Mobile Phone by solar energy. In the beginning, a comprehensive overview to the energy harvesting concept and technologies is presented. Then the Application of Charging Mobile Phone by solar energy its efficiency to charge the aimed batteries under sunlight or an indoor artificial light.
\end{abstract}

\section{Introduction}

Photovoltaic energy is the conversion of sunlight into electricity. A photovoltaic cell, commonly called a solar cell or PV, is the technology used to convert solar energy directly into electrical power.[1]Sunlight is composed of photons, or particles of solar energy .These photons contain various amounts of energy corresponding to the different wavelengths of the solar spectrum. When photons strike a photovoltaic cell, they may be reflected, pass right through, or be absorbed. Only the absorbed photons provide energy to generate electricity The sun has the ability to generate free and almost unlimited energy that can be converted into electricity using solar panel. The converted energy from the sun can be used to power any kind of electricity including intermediate storage battery as solar powered mobile phone charger

\section{Literature Review}

\subsection{Photovoltaic System Components}

Photovoltaic systems consist of solar panels, a battery, charge controller, and an inverter. The lifetime of the panels is typically 20 to 25 years, which is considered the lifetime of the total system. The battery stores the power from the sun and is used when the sun isn't shining or during cloudy weather. Two types of batteries can be used, deep-cycle and starter batteries. The deep-cycle batteries are more efficient and most commonly used, The charge controller regulates the current added to and drawn from the battery in order to maximize the battery lifetime and for user safety. Because photovoltaic systems produce a direct current, the inverter is necessary especially when the end-user requires an alternating current.

\subsection{Photovoltaic Cell}

A device that produces an electric reaction to light, producing electricity. PV cells do not use the sun"s heat to produce electricity. They produce electricity directly when sunlight interacts with semiconductor materials in the PV cells. "A typical PV cell made of crystalline silicon is 12 centimeters in diameter and 0.25 millimeters thick. In full sunlight, it generates 4 amperes of direct current at 0.5 volts or 2 watts of electrical power [2].

\subsection{Solar Panel}

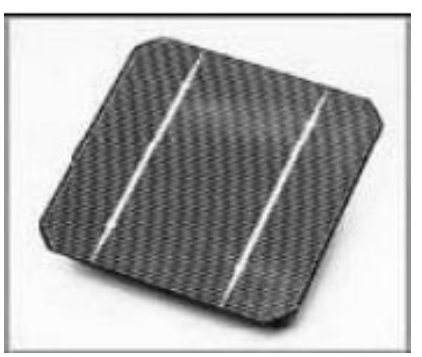

Figure 1 Photovoltaic cell

The solar panel is the power source of all photovoltaic installation. It is the result of a set of photovoltaic cells in series and parallel. Solar panel gives power to battery or inverter through charge controller (Regulator). [3].

Basic theory of photovoltaic cell :-

Photovoltaic cells are made of silicon or other semi conductive materials that are also used in LSIs and transistors for electronic equipment. Photovoltaic cells use two types of semiconductors, one is P-type and other 
is N-type to generate electricity [4]. When sunlight strikes a semiconductor, it generate pairs of electrons (-) and protons (+).

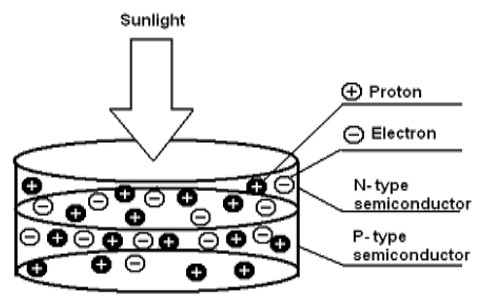

Figure 2 Basic Theory of Photovoltaic cell 1

When an electron (-) and a proton (+) reach the joint surface between the two types of semiconductors, the former is attracted to N-type and the latter to the P-type semiconductor. Since the joint surface supports only one way traffic, they are not able to rejoin once they are drawn apart and separated

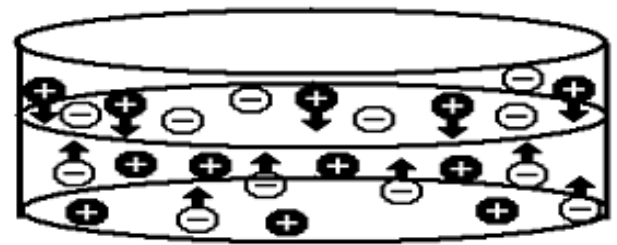

Figure 3 Basic theory of photovoltaic cell 2

Since the N-type semiconductor now contains an electron (-), and P-type semiconductor contains a proton $(+)$, an electromotive (voltage) force is generated. Connect both electrodes with conductors and the electrons runs from $\mathrm{N}$ - type to P-type semiconductors, and the proton from P-type to N-type semiconductors to make an electrical current.

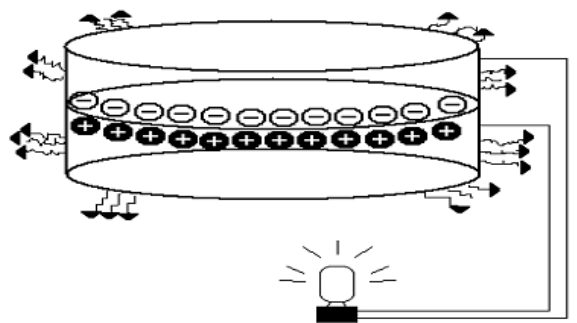

Figure 4 Basic theory of photovoltaic cell 3

\subsection{Series and parallel connection of PV cells}

Solar cells can be thought of as solar batteries. If solar cells are connected in series, then the current stays the same and the voltage increases [4].

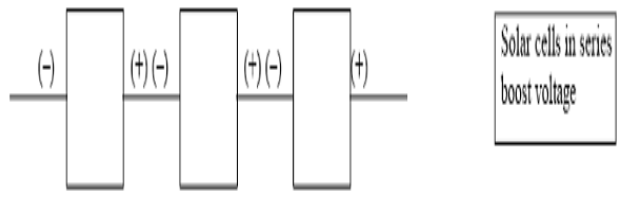

Figure 5 Series connection of cells

If solar cells are connected in parallel, the voltage stays the same, but the current increases.
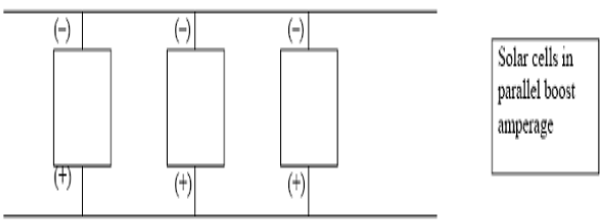

Figure 6 Parallel connection of cells 


\subsection{Types of Photovoltaic's cells}

There are essentially two types of PV technology, crystalline and thin-film. Crystalline can again be broken down into two types:

1. Monocrystalline Cells - These are made using cells cut from a single cylindrical crystal of silicon. While monocrystalline cells offer the highest efficiency (approximately 18\% conversion of incident sunlight), their complex manufacturing process makes them slightly more expensive.

2. Polycrystalline Cells - These are made by cutting micro-fine wafers from ingots of molten and recrystallized silicon. Polycrystalline cells are cheaper to produce, but there is a slight compromise on efficiency (approximately 14\% conversion of incident sunlight). possible.PV is depositing an ultra thin layer of photovoltaic material onto a substrate. The most common type of thin-film PV is made from the material a-Si (amorphous silicon), but numerous other materials such as CIGS (copper indium/gallium diselenide) CIS (copper indium selenide), CdTe (Cadmium Telluride), dye-sensitized cells and organic solar cells are also possible.

Applications for (PV) such as remote buildings, such as schools, community halls, and clinics, can benefit from solar energy. In developing regions, central power plants can provide electricity to homes via a local wired network, or act as a battery charging station where members of the community can bring batteries to be recharged.

PV systems can be used to pump water in remote areas as part of a portable water supply system. Specialized solar water pumps are designed for submersible use or to float on open water. Large-scale desalination plants can also be PV powered using an array of PV modules with battery storage.

PV systems are sometimes best configured with a small diesel generator in order to meet heavy power requirements in off-grid locations. With a small diesel generator, the PV system does not have to be sized to cope with the worst sunlight conditions during the year. The diesel generator can provide back-up power that is minimized during the sunniest part of the year by the PV system. This keeps fuel and maintenance costs low. [5]

\subsection{Charge Controller}

The main task of a charge controller in this experiment is to prevent battery by overcharging.

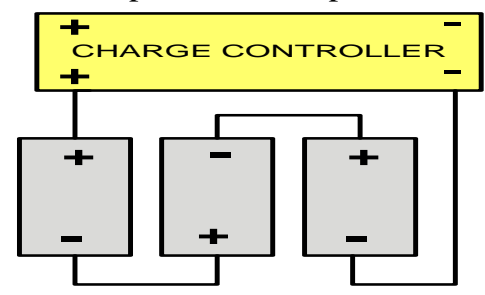

Figure 7 Charge Controller

\subsection{Battery Storage}

In this proposal, the type of batteries is QV410, each battery has DC voltage at $4 \mathrm{~V} \mathrm{DC}$. The batteries bank in serial for this system is 3 unit and capacity $1000 \mathrm{~mA}$ heach.

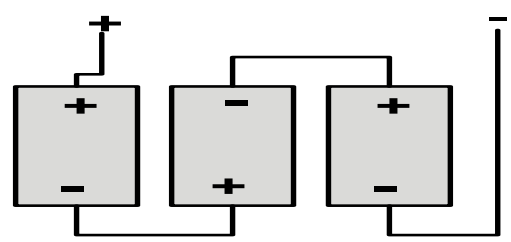

Figure 8 Battery Bank in Serial with $12 \mathrm{~V}$

\subsection{Protection of Photovoltaic Array}

Protection of Photovoltaic is provide protection for overcurrent or short circuit. A fuse is link to photovoltaic array will protect from current faults and minimize any hazard to the device. The fuse will disconnect (PV) system if the current exceeds the limit of the fuse.

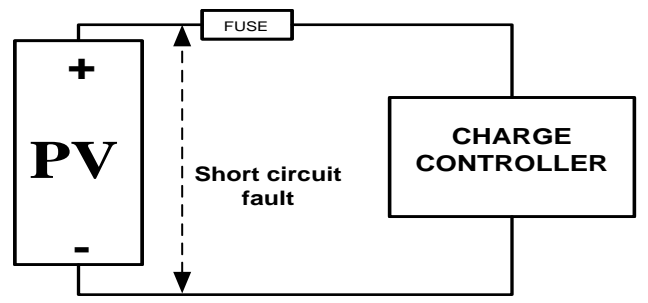

Figure 9 Protection of Photovoltaic 


\subsection{Photovoltaic System Components}

Photovoltaic systems consist of solar panels, a battery, charge controller, and an inverter. The lifetime of the panels is typically 20 to 25 years, which is considered the lifetime of the total system. The battery stores the power from the sun and is used when the sun isn't shining or during cloudy weather. Two types of batteries can be used, deep-cycle and starter batteries. The deep-cycle batteries are more efficient and most commonly used, The charge controller regulates the current added to and drawn from the battery in order to maximize the battery lifetime and for user safety. Because photovoltaic systems produce a direct current, the inverter is necessary especially when the end-user requires an alternating current.

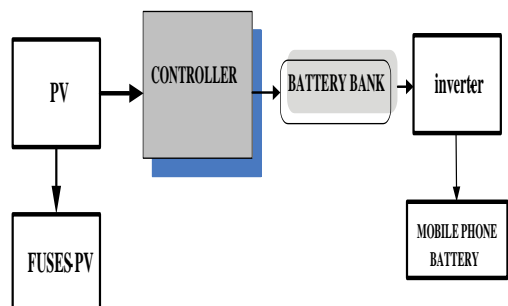

Figure 10 PV Portable Mobile Phone Charger System

Experiment To Charge Mobile Phone Battery

\section{Data Analysis}

\subsection{Load Power Requirement}

The power rating of NOKIA mobile phone battery type BL-4U as in chapter above, presented below:

Voltage : $3.7 \mathrm{~V}$ DC

Capacity: $1000 \mathrm{mAh}$

The power draw of this battery, hence:

$P=V \times I$

$P=3.7 \times 1000 m A=3,7$ watt

\subsection{Battery Bank}

Battery bank is used to provide energy storage. If the mobile phone battery is $1000 \mathrm{mAh}$ and $3,7 \mathrm{~V}$ DC it is need 37 watt, so the battery bank must capable to back up it. The battery bank size that we use in this design and the number of batteries required for the developed system was obtained as shown below:

1. Battery type QV410

2. Voltage 4 volts in serial $=12$ volt DC

3. $1000 \mathrm{mAh}$

Total power of the battery bank:

$P=V \times I$

$P=12 \times 1000 m A=12 W h$

\subsection{PV Sizing}

With the total power consumption of the battery charger known, the number of solar panels was obtained as shown below :

Step PV sizing Value

1. Daily PV output needed $12 \mathrm{Wh}$

2. $30 \%$ PV Power Loss Estimation $30 \% \times 12 \mathrm{Wh}=3,6 \mathrm{Wh}$

3. Average sun hours / day 6 hour

4. Minimum system size $(12 \mathrm{Wh}+3,6 \mathrm{Wh}): 6 \mathrm{~h}=2,6 \mathrm{~W}$

5. Chosen system module > 2,6 watt

From description above, we need minimum PV system module requirement is 2,6 watt.

\subsection{Inverter}

An inverter is an electrical device that converts direct current (DC) source such as batteries, solar panels, or fuel cellsto alternating current(AC). One of popular inverter is using IC N555 which invert $12 \mathrm{~V}$ DC to 220 AC. An inverter with IC n 555 shown in figure 3.6 


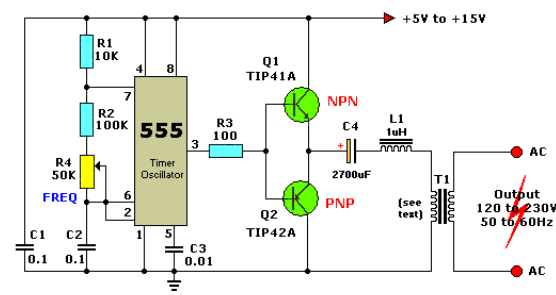

Figure 11 DC to AC Inverter With IC 555

IC 555 configured for Low Frequency Oscillator. Frequency can be changed in the frequency range 50$60 \mathrm{~Hz}$ by change R4 potentiometer value .IC 555 feeds the output (amplified by Q1 and Q2) for the input of the transformer T1, a reverse-connected filament transformer with the necessary step-up turns ratio. Capacitor C4 and coil L1 filter the input to T1, assuring that it is a sine wave effectively.

Inverter Calculation:

1.Winding calculation:

The voltage per turn VT $=\mathrm{C} \sqrt{ } \mathrm{KVA} \quad$ (1)

where $\mathrm{C}$ is a constant $(0.56)$

Note: Papparent $=$ Pinst $/$ Power factor

where Pinst $=100 \mathrm{~W}$

Power factor $=0.8$

Hence Papparent $=100 / 0.8$

$$
\begin{aligned}
& =125 \mathrm{VA} \\
& =0.125 \mathrm{KVA}
\end{aligned}
$$

Substituting the value of Papp into equation 1, the value of VT is obtained as shown below:

$$
\begin{aligned}
\mathrm{VT} & =\mathrm{C} \sqrt{\mathrm{KVA}} \\
& =0.56 \sqrt{ } 0.125 \\
& =0.198 \text { volts } / \text { turn }
\end{aligned}
$$

of turns in the primary side:

$\mathrm{N} 1=\mathrm{V} 1 / \mathrm{VT}$

where :

$\mathrm{V} 1=12$ volts, $\mathrm{VT}=0.198, \mathrm{~N} 1=12 / 0.198=60.6$ turns

of turns in the secondary side:

$\mathrm{N} 2=\mathrm{V} 2 / \mathrm{VT}$

where $\mathrm{V} 2=220$ volts, $\mathrm{VT}=0.198$

$\mathrm{N} 2=220 / 0.198=111$ turns

2. Current rating of inverter:

Given that $\mathrm{P}=\mathrm{IV}$

Where

$\mathrm{P}=$ Power in watts

$\mathrm{I}=$ Current in amps

$\mathrm{V}=$ Voltage in volts

Current rating for the primary side of the Inverter is given by:

$$
\begin{aligned}
& \mathrm{I}=\mathrm{P} / \mathrm{V} \\
& \mathrm{I}=100 / 12=8.33 \mathrm{amps}
\end{aligned}
$$

Current rating for the secondary side of the Inverter is given by:

$\mathrm{I}=\mathrm{P} / \mathrm{V}$

$\mathrm{I}=100 / 220=0.45 \mathrm{amps}$

The standard wire guage (SWG) used in the design can be found in wiring datasheet and is capable of withstanding the calculated currents. In this design, enamel led copper wire is used.

\section{Fuse rating}

The fuse rating for the inverter which is the full load current that can be drawn from the inverter is obtained as shown below:

Ifl $=$ KVA rating $/$ Output voltage 
$=100 / 220$

$=0.4545$ amps

iv. Frequency calculation:

The output frequency of $50 \mathrm{~Hz}$ was achieved using the formula obtained from the SG3524 datasheet;

$\mathrm{F}=2.18 /(\mathrm{RTCT})$

(8)

where

$\mathrm{f}=$ frequency,

$\mathrm{C}=$ capacitor,

$\mathrm{R}=$ Resistor

Hence, $50 \mathrm{~Hz}=2.18 /(\mathrm{RT} \times 0.104 \mu \mathrm{F})$

$2.18=50 \times \mathrm{RT} \times 0.104 \mu \mathrm{F}$

$\mathrm{RT}=2.18 /(50 \times 0.104 \mu \mathrm{F})$

$\mathrm{RT}=220 \mathrm{~K} \Omega$

Hence, to achieve a frequency of $50 \mathrm{~Hz}$, a variable resistor of $220 \mathrm{~K} \Omega$ was used.

\section{Conclusion}

This paper has successfully presented a functional solar solution for mobile charging centers in south of libya. Though the system has a high initial cost, it has a higher yield on the long-run. The energy from this system is environmentally friendly devoid of noise pollution and toxic gas emission. This system saves these mobile charging Most of the materials used in the construction of this system are readily available in the market.

\section{References}

[1] Energy Information Administration, Electric Power Annual, Form EIA-860, Annual Electric Generator Report database, 2006

[2] R. Messenger, J. Ventre, "Photovoltaic Systems Engineering," 1st Ed. New York: CRC Press, 2000, pp.63-64, pp. 53, 64, $297-303$.

[2] [http: Solar Electric Systems] "Chapter Three Introduction to Solar Electric Systems" available atwww.kysolar.org/ky_solar_energy_guide/chapters/Chapter_3_PVintro.pdf

[3] From site www. Solartradingpost.com.

[4] [http: Series and Parallel connection] "Series and Parallel Wiring" available at www.termpro.com/articles/spkrz.html.

[5] http://www.esdalcollege.nl/eos/vakken/na/zonnecel.htm 